\title{
Palynology of the genus Pulicaria Gaertn. (Asteraceae, Inuleae, Inulinae) in the Iberian Peninsula
}

\author{
A. Pereira Coutinho* and A. M. Dinis* \\ * Laboratory of Electron Microscopy and Palynology, Department of Botany, Faculty of Sciences \\ and Technology, University of Coimbra, 3001-455 Coimbra, Portugal \\ cafe@bot.uc.pt
}

Pulicaria is the third largest genus of the tribe Inuleae. It comprises ca. 80 species of shrubs, shrublets and herbs with a European, North African and Asian distribution. All of the 5 European species are represented in the Iberian Peninsula. The genus has taxonomic problems, as recent cladistic analysis [1,2] showed that, like the other two great genera of Inuleae (Inula and Blumea), Pulicaria is a paraphyletic taxon. In fact, the species investigated so far were placed in two distinct clades [1, 2]. Moreover, the species status of Pulicaria microcephala, a Portuguese endemism of Berlengas Islands, is still controversial [3]. As already demonstrated by several authors, the palynological data are of great importance to understand the evolution, taxonomy and ecology of the Asteraceae. However, in spite of a few relevant contributions [4], the palynology of Pulicaria is still insufficiently known. In the present work we investigated the palynology of the Iberian species of Pulicaria using light (LM) and scanning electron microscopy (SEM). The exine structure of Pulicaria paludosa was also investigated using transmission electron microscopy (TEM).

Pollen grains were collected from herbaria specimens and acetolysed. Then, they were mounted in silicone oil and measured (LM), or else treated with ultra-sounds (35 kc/s, 1h), dehydrated in pure acetone, sputter coated with gold-palladium and examined with the SEM. Statistical analysis was with ANOVA followed by the Tukey Multiple Comparison Test. For TEM examination the acetolysed pollen was conventionally fixed in glutaraldehyde and osmium tetroxide and embedded in low viscosity resin [4].

TEM and SEM (fractured exine) examinations revealed the existence of a typical senecioid pattern of exine for all the taxa investigated, i.e. caveate, with a thin foot layer and vestigial foramina [4]. Also, all taxa investigated had pollen grains 3-zonocolporate and echinate-microperforate (Figs 1-6). Nevertheless, the quantitative (e.g. length of the polar axis) and qualitative (e.g. shape of the spines) pollen data allowed us to individualize all the species examined. In fact, the spines in the pollen of $P$. vulgaris are generally abnormal in shape and/or size (Fig 6.) and those in $P$. microcephala and in the other species are, respectively, contracted (Fig 2.) and attenuated (Figs. 1 and 3-5) in the apex. The polar axis of $P$. odora and $P$. sicula is larger $(>23 \mu \mathrm{m})$ than the polar axis of $P$. paludosa and $P$. dysenterica $(\leq 23 \mu \mathrm{m})$. Also, the maximal diameter of the micro-perforations in the exine of $P$. odora and of $P$. sicula is, respectively, larger and smaller than $0.7 \mu \mathrm{m}$ and the width of the pollen ectoapertures of $P$. paludosa is larger $(>4.2 \mu \mathrm{m})$ than the width of the pollen ectoapertures of $P$. dysenterica $(\leq 4.2 \mu \mathrm{m})$.

The considerable pollen variability of Pulicaria supports the cladistic analysis that split this genus in more than one monophyletic group [1,2]. In addition, the existence of Pulicaria microcephala as an independent species [3] is supported by our results. 
References

[1] A. Anderberg, P. Eldënas, R. Bayer, M. Englund. Org Div Evol 5 (2005) 135.

[2] J. Francisco-Ortega, P. Seon-Joo, A. Santos-Guerra, A. Benabid, R. Jansen. Biol J Linn Soc 72 (2001) 77.

[3] F. Almada, M. Cruz, C. Gomes, D. Gonçalves, J. Rodrigues. Bol Soc Brot, ser 2, 67 (1995) 43.

[4] A. Pereira Coutinho, A. M. Dinis. Pl. Syst Evol 269 (2007) 159.
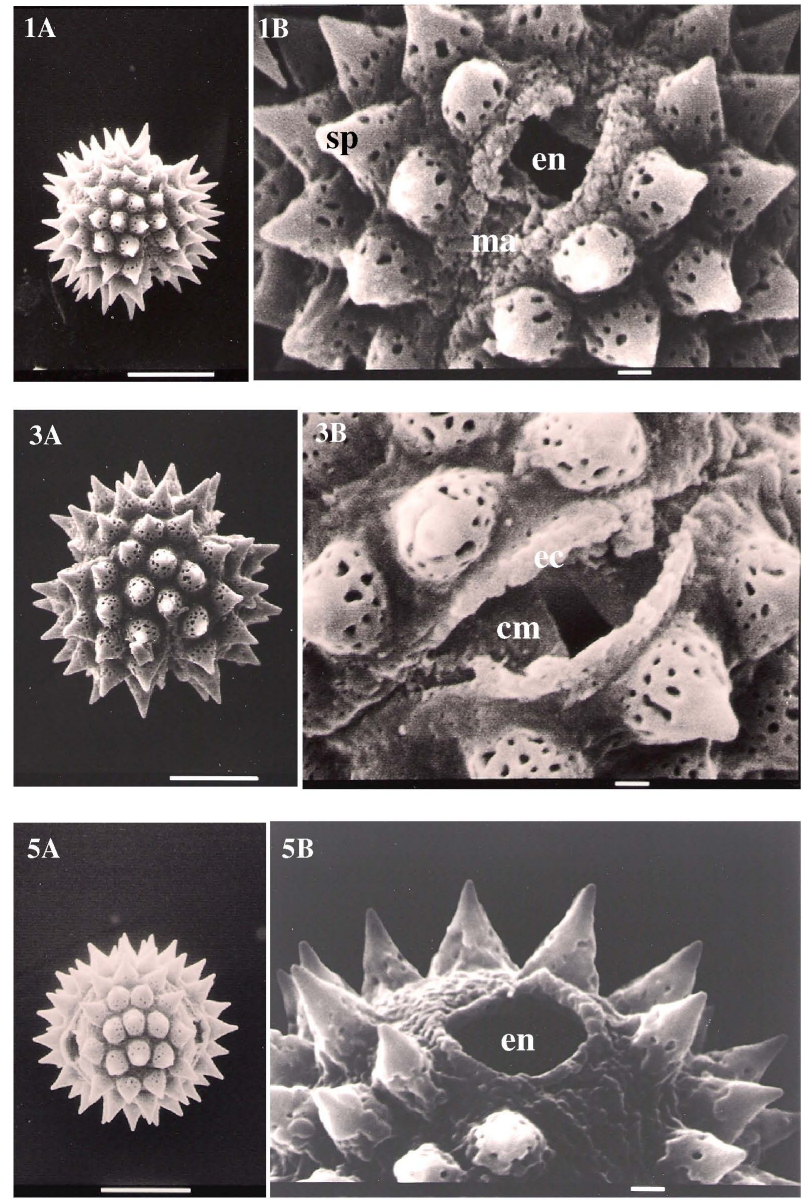
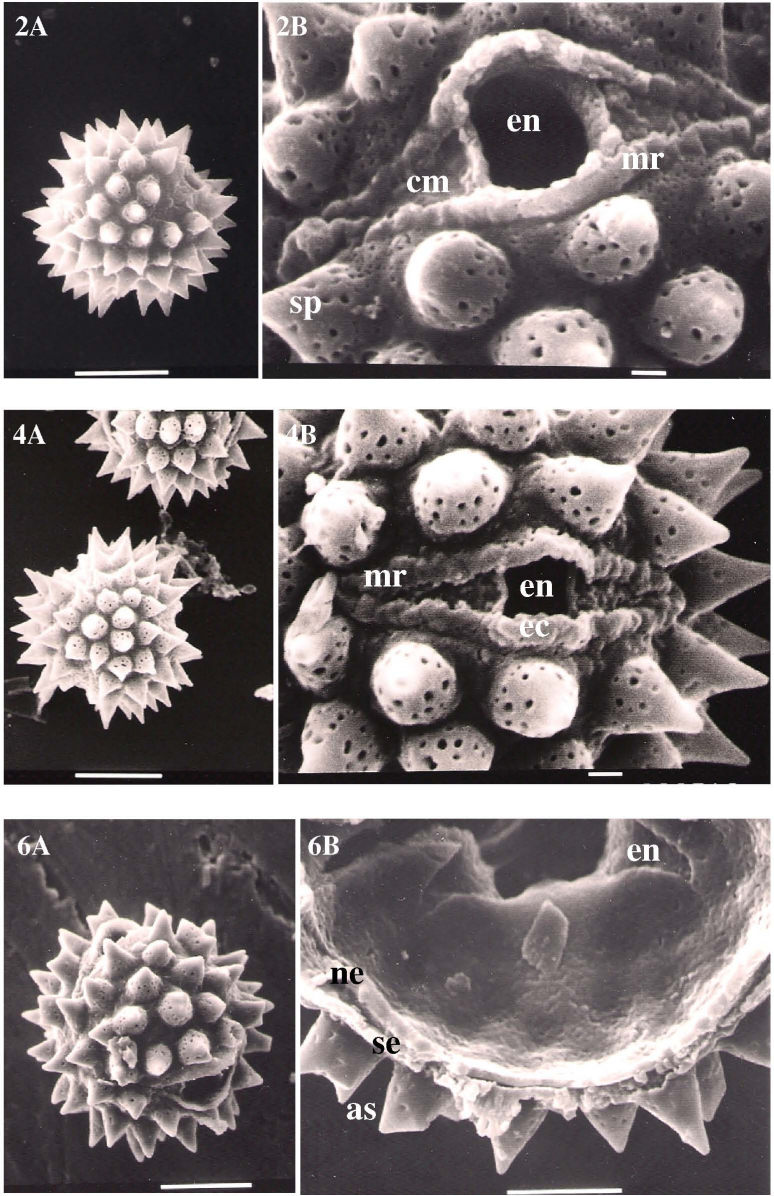

Fig. 1. P. dysenterica pollen grains. A. Polar view. B. Detail of the sculpture. Fig. 2. P. microcephala pollen grains. A. Polar view. B. Detail of the sculpture.

Fig. 3. P. odora pollen grains. A. Polar view; B. Detail of the sculpture.

Fig. 4. P. paludosa pollen grains. A. Polar view. B. Detail of the sculpture.

Fig. 5. P. sicula pollen grains. A. Equatorial view. B. Detail of the sculpture.

Fig. 6. P. vulgaris pollen grains. A. Equatorial view. B. Detail of a fractured exine.

Scale bars: $10 \mu \mathrm{m}$ (Figs. 1A, 2A, 3A, 4A, 5A and 6A), $5 \mu \mathrm{m}$ (Fig. 6B), $1 \mu \mathrm{m}$ (Figs. 1B, 2B, 3B, 4B and $5 \mathrm{~B})$.

Legend for all figures: $s p$ - spine; $a s$ - abnormal spine; $s e$ - sexine; $n e$ - nexine; $e c$ - ectoaperture; $m a$ - mesoaperture; $e n$ - endoaperture; $\mathrm{cm}$ - colpal membrane $\mathrm{mr}$ - margo. 